\title{
Simulating Southern Hemisphere extra-tropical climate variability with an idealised coupled atmosphere-ocean model
}

\author{
H. Kurzke ${ }^{1, *}$, M. V. Kurgansky ${ }^{2}$, K. Dethloff ${ }^{1}$, D. Handorf ${ }^{1}$, S. Erxleben ${ }^{1}$, D. Olbers ${ }^{3}$, C. Eden ${ }^{4}$, and M. Sempf ${ }^{5, * *}$ \\ ${ }^{1}$ Alfred Wegener Institute for Polar and Marine Research, Research Unit Potsdam, Potsdam, Germany \\ ${ }^{2}$ A. M. Obukhov Institute of Atmospheric Physics, Russian Academy of Sciences, Moscow, Russia \\ ${ }^{3}$ Alfred Wegener Institute for Polar and Marine Research, Bremerhaven, Germany \\ ${ }^{4}$ Institute of Oceanography, University of Hamburg, Hamburg, Germany \\ ${ }^{5}$ SDA Software Design Ahnert GmbH, Berlin, Germany \\ * current address: Institute for Physics and Astronomy, Potsdam University, Potsdam, Germany \\ ** formerly at: Max Planck Institute for Plasmaphysics, Muenchen-Garching, Germany
}

Correspondence to: K. Dethloff (klaus.dethloff@awi.de)

Received: 13 July 2011 - Published in Geosci. Model Dev. Discuss.: 16 August 2011

Revised: 8 August 2012 - Accepted: 20 August 2012 - Published: 19 September 2012

\begin{abstract}
A quasi-geostrophic model of Southern Hemisphere's wintertime atmospheric circulation with horizontal resolution $\mathrm{T} 21$ has been coupled to a global ocean circulation model with a resolution of $2^{\circ} \times 2^{\circ}$ and simplified physics. This simplified coupled model reproduces qualitatively some features of the first and the second EOF of atmospheric $833 \mathrm{hPa}$ geopotential height in accordance with NCEP data. The variability patterns of the simplified coupled model have been compared with variability patterns simulated by four complex state-of-the-art coupled CMIP5 models. The first EOF of the simplified model is too zonal and does not reproduce the right position of the centre of action over the Pacific Ocean and its extension to the tropics. The agreement in the second EOF between the simplified and the CMIP5 models is better. The total variance of the simplified model is weaker than the observational variance and those of the CMIP5 models. The transport properties of the Southern Ocean circulation are in qualitative accord with observations. The simplified model exhibits skill in reproducing essential features of decadal and multi-decadal climate variability in the extratropical Southern Hemisphere. Notably, $800 \mathrm{yr}$ long coupled model simulations reveal sea surface temperature fluctuations on the timescale of several decades in the Antarctic Circumpolar Current region.
\end{abstract}

\section{Introduction}

Understanding natural variability on interannual-tomultidecadal time scales is an important and longstanding problem in climate dynamics. In this study, we will be focusing on the interannual, decadal and multidecadal variability in the extra-tropical Southern Hemisphere (SH) and on the relative role of the atmosphere and the ocean in its explanation. The principal mode of the aforementioned variability, which is not directly related to El Niño-Southern Oscillation (ENSO), has been named the High Latitude Mode (HLM), or the Southern Annular Mode (SAM), or the Antarctic Oscillation (AAO) (Thompson and Wallace, 2000). The AAO is a zonally symmetric pattern in the sea level pressure field with opposite signs between the Antarctica and midlatitudes, which originates in the atmosphere-only dynamics. However, the atmosphere-ocean coupling over the largely aquatic $\mathrm{SH}$ undoubtedly plays an important role in shaping the leading modes of extratropical low-frequency climate variability, but the operating mechanisms remain obscure.

An important aspect concerns the Antarctic Circumpolar Current (ACC) transport. Olbers and Lettmann (2007) have applied a global ocean circulation model with simplified physics (the barotropic-baroclinic-interaction model BARBI of Olbers and Eden (2003). In one of their main experiments, BARBI has been forced by an artificial wind stress 
constructed from the first three empirical orthogonal functions (EOFs) of the National Center for Environmental Prediction/National Center for Atmospheric Research (NCEPNCAR) combined with a temporal variability according to an autoregressive process. BARBI can be forced by a surface wind stress and a surface source of the baroclinic potential energy (defined in Appendix A), but Olbers and Lettmann (2007) set the latter term to zero and a purely wind-driven variability of the Southern Ocean was studied. A $1800 \mathrm{yr}$ BARBI run with this SAM-type forcing showed that "the Southern Mode" of variability (cf. Hughes et al., 1999) with coherence between ACC transport, Southern Ocean windstress and bottom pressure extends to periods well above decadal. For these periods, baroclinic processes come into play and the baroclinic potential energy, as manifestation of the baroclinic pressure, takes control of the ACC transport. In these circumstances BARBI behaves similar to Hasselmann (1976) stochastic climate model, with the ACC transport as the fast variable, the baroclinic pressure gradient across Drake Passage as the slow variable, and the wind stress as red noise forcing (the latter in contrast to the classical stochastic model).

This study aims at the work of Olbers and Lettmann (2007) by coupling the oceanic BARBI to an idealised three-level quasi-geostrophic model of the atmospheric circulation over the Southern Hemisphere (SH). The oceanic component of the coupled atmosphere-ocean model, originally developed for the SH by Olbers and Eden (2003), successfully simulates the wind-driven oceanic circulation in the $\mathrm{SH}$, but has certain weaknesses in reproducing the intensity of oceanic gyres in the Northern Hemisphere (NH) Atlantic Ocean, where thermohaline processes are of primary importance. The atmospheric model was initially developed by Sempf et al. $(2007 \mathrm{a}, \mathrm{b})$ for the $\mathrm{NH}$, where the ocean-continent contrasts are by far more pronounced, and is now applied to the SH. Since the atmospheric model is a quasi-geostrophic one, assuming anti-symmetric streamfunction with respect to the equator, any inter-hemispheric atmospheric interactions are out of bounds. Interactions between the $\mathrm{SH}$ and the NH occur only via the global oceanic circulation. To keep the model set-up in the first step simple enough, the interactive coupling between atmospheric and oceanic processes has been restricted to the SH. The annual mean atmospheric wind forcing for the $\mathrm{NH}$ oceanic circulation is provided by winds from the European Center for Medium Weather Forecast (ECMWF) reanalysis data and no interactive atmosphere-ocean coupling is allowed in the NH. Thus, the coupled atmosphere-ocean model is considered for the whole globe, but only its $\mathrm{SH}$ atmospheric part is used to interact with the Southern Ocean.

Our model occupies an intermediate position in the hierarchical set of models ranging from comprehensive state-ofthe-art coupled global circulation models (coupled GCMs, or CGCMs) to very idealised coupled models, which have omitted a fully dynamical atmospheric component, including ocean models coupled to energy-balance atmospheric models. Compared to the latter models, we opt for a simplified but dynamically more solid framework via the use of the quasigeostrophic atmospheric component, similar in this respect to, e.g., Opsteegh et al. (1998), Haarsma et al. (2000), Hogg et al. (2003), and Hogg and Blundell (2006). The main aim of this work is the development of a simplified dynamical climate system coupling atmosphere and ocean subsystems including essential nonlinear dynamical features and increased realism with respect to internal coupled climate modes. This novel model bridges previous research dealing with the construction of idealised atmospheric and oceanic circulation models. We study intrinsic extra-tropical sources of climate variability in the Southern Hemisphere. The Southern Hemisphere is chosen because the oceanic BARBI component of the coupled model most successfully simulates the winddriven oceanic circulation in the SH.

In this idealised modeling set-up, we omit dynamical interaction between the atmosphere and the ocean in the tropics, notably the ENSO phenomenon, and focus exclusively on extratropical sources of the climate variability over mid- and high SH latitudes. There are other inherent simplifications and idealisations in the model, described in Sect. 2. The primary goal of this study with a conceptual model tool is to better understand the role of the extratropical atmosphere-ocean coupling in the SH in producing and modifying interannualto-multidecadal climate variability.

This paper is organised as follows. In Sect. 2, we explain the constructed coupled atmosphere-ocean model. Section 3 describes the model set-up and presents the results of $1000 \mathrm{yr}$ model simulations. The obtained results are discussed and conclusions are drawn in Sect. 4. In Appendix A, the used version of oceanic model BARBI is described in more detail. In Appendix B, we show the details of atmosphere-ocean thermal coupling and relate the baroclinic potential energy in BARBI to the sea surface temperature (SST).

\section{Model description}

The coupled atmosphere-ocean model consists of three modules: for the atmosphere, the ocean and the coupling procedure, respectively.

\subsection{Atmospheric module}

The dynamic core of the atmospheric module is the quasigeostrophic potential vorticity equation. It is a hemispheric 3-layer model with a T21 spectral resolution. The spectral interaction coefficients are found by transformation from the spectral space onto a grid with 64 points in the zonal direction, which corresponds to a resolution of $5.625^{\circ}$ in longitude, and with 32 points in the meridional direction (the Gaussian latitudes). The latter points are symmetric with respect to the equator, i.e., there are 16 points in the $\mathrm{SH}$, but the 


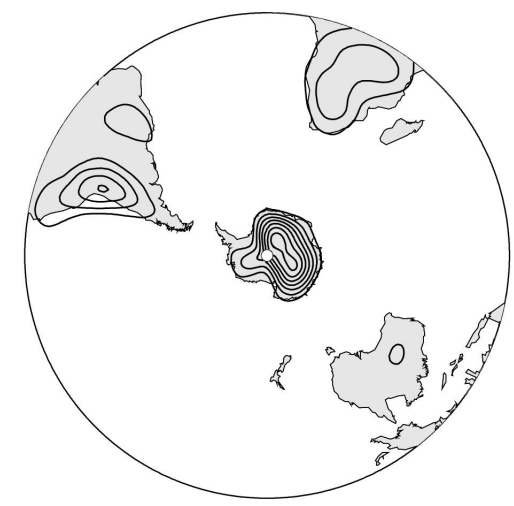

(a)

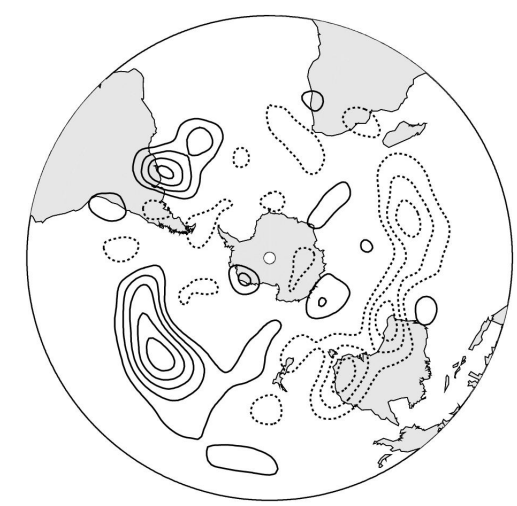

(b)

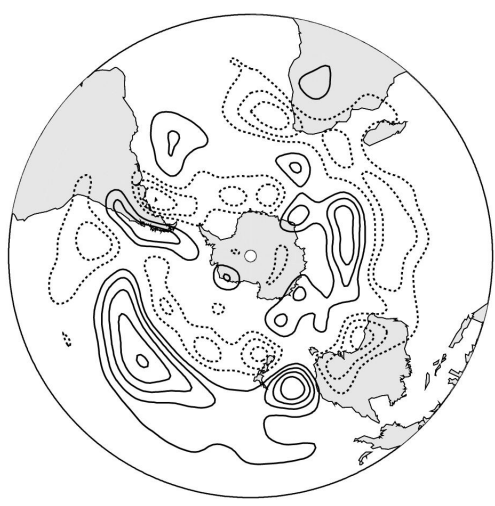

(c)

Fig. 1. (a) T21 topography of the Southern Hemisphere. Contour interval is $500 \mathrm{~m}$. (b) Non-zonal part of austral wintertime (JJA) extratropical diabatic heating at $300 \mathrm{hPa}$ derived from NCEP-NCAR reanalysis data and used in the atmospheric module. Contour interval is $0.25 \mathrm{~K} \mathrm{day}^{-1}$ without zero line. Negative values are dashed. (c) The same as in the middle, but for $700 \mathrm{hPa}$.

distance between them slightly varies according to the relative weight of different Gaussian latitudes. It is a dry model. That is, no clouds, no precipitation (rainfall) and no latent heat are taken into account explicitly. Non-zonal components of extra-tropical thermal forcing (radiative equilibrium temperature fields) have been adjusted in a way that, on the time mean, realistic patterns of non-zonal extra-tropical diabatic heating are acting in the model. The zonal components of the radiative equilibrium temperature fields and the surface forcing, which acts as a substitute for the absent baroclinicity within the lowermost layer and helps to enforce low-level westerlies, have been tuned to produce a zonal climatology as realistic as possible. The adjustments of forcing are made by an automatic iterative procedure, described in Sempf et al. (2005, 2007a,b), adapted to the SH is abbreviated as GS3LM, hereafter.

\subsection{Oceanic module}

The oceanic module uses vertically integrated dynamical equations in terms of the streamfunction of volume transport, $\Psi$, the baroclinic potential energy of individual water columns scaled by a constant reference seawater density, $E$, and a baroclinic velocity moment, $\boldsymbol{u}^{*}$ (see, Appendix A). This is a simplified version of BARBI (Olbers and Eden, 2003; Olbers et al., 2007; Olbers and Lettmann, 2007) which accounts for a joint effect of baroclinicity and bottom relief (JEBAR Sarkisyan and Ivanov, 1971). JEBAR is a prominent source of vorticity in addition to the windstress curl and flow across the geostrophic contours in a vertically averaged view of the flow. The used oceanic module has 181 grid points in the zonal direction and 75 grid points in the meridional direction. It corresponds to a resolution of $2^{\circ} \times 2^{\circ}$ longitude/latitude. There is a grid asymmetry with respect to the equator: an integration area extends from $77^{\circ} \mathrm{S}$ to $71^{\circ} \mathrm{N}$. The lateral ocean boundary conditions assume the no-slip condi- tion $\mathbf{u}=0$ (see notations in Appendix A) and vanishing fluxes of potential energy.

\subsection{Coupling module}

The design and numerical implementation of the coupling module is based on a beta version of Modular Ocean Model MOM2 (Version 2.0), as "a stepping stone" to MOM3 (Pacanowski, 1996; Pacanowski and Griffies, 2000).

\subsection{Atmospheric GS3LM versus oceanic BARBI}

GS3LM simulates the quasi-geostrophic evolution of SH atmospheric flow streamfunctions at the three vertical levels 167,500 , and $833 \mathrm{hPa}$ under perpetual SH winter conditions. Southern Hemisphere's T21 topography (Fig. 1a) acts as orographic forcing. Diabatic heating is established by thermal relaxation towards predefined radiative equilibrium temperature fields at the auxiliary model pressure levels 333 and $667 \mathrm{hPa}$. The relaxation timescale is 22.7 days. Slightly differently to the NH (Sempf et al., 2005), the temperature lapse rate is fixed to $2.9 \mathrm{~K} \mathrm{~km}^{-1}$ at $333 \mathrm{hPa}$ and $6.5 \mathrm{~K} \mathrm{~km}^{-1}$ at $667 \mathrm{hPa}$. The relaxation time of Ekman friction equals to 2.2 days. Other parameter settings are the same as in Sempf et al. (2005). The cited paper describes an automatic iterative procedure of the atmospheric model pre-tuning before coupling to the ocean model. First, the model's timemean wind profiles are compared with and then are iteratively tuned towards observed SH wintertime zonal winds taken from NCEP-NCAR reanalysis data. Second, within the same iterative procedure the model's time-mean nonzonal diabatic heating is compared with and then is tuned towards the non-zonal part of SH wintertime heating fields at 300 and $700 \mathrm{hPa}$, derived from observations by Nigam et al. (2000). The latter fields have been attenuated near the equator and are shown in Fig. 1b-c. Thus tuned, GS3LM exhibits a pronounced internal "ultra-low-frequency" variability that 


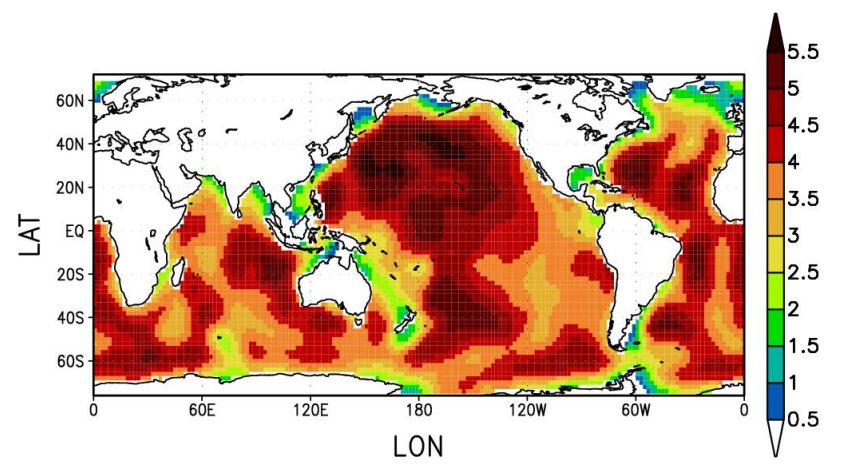

Fig. 2. Bottom topography of the oceans with $2^{\circ} \times 2^{\circ}$ longitude and latitude resolution and realistic coast lines (black contour). Zero bottom isohyps is omitted. Contour (colour) interval is $500 \mathrm{~m}$.

manifests itself in various atmospheric fields, similar in this respect to the pioneering simulations by James and James (1992); see a recent discussion of the latter work in Vallis (2010).

BARBI accounts for the JEBAR effect in the vertically averaged vorticity equation without any depth scaling as, e.g., required in quasi-geostrophic models. Considering the JEBAR-term in the vorticity equation necessitates a prognostic equation for the baroclinic potential energy $E$. When the baroclinic flow component is accounted for, the governing equations cannot be written in a closed form, but give rise to an infinite set of equations for the moments of the density field, with $E$ as the first moment, and also for the moments of the baroclinic velocity.

In this work, a simple truncation and subsequent closure of this infinite set of equations is made after Olbers and Eden (2003). As in Olbers and Eden (2003), an account for nonlinearity is made in the thermohaline balance equation only. Advection of momentum in the momentum balance equation is neglected since the emphasis is placed mainly on largescale flows (Olbers and Eden, 2003). The ocean bottom topography in $2^{\circ} \times 2^{\circ}$ longitude/latitude resolution is shown in Fig. 2. The parameters of the oceanic module were chosen so that the transport through Drake Passage was within the range $70-150 \mathrm{~Sv}\left(1 \mathrm{~Sv}=10^{6} \mathrm{~m}^{3} \mathrm{~s}^{-1}\right)$. This comparison is especially useful because there are good oceanographic measurements for Drake Passage, in contrast to the rest of Southern Ocean. Based on various previous studies, Cunningham et al. (2003) present the mean estimate $137 \pm 8 \mathrm{~Sv}$.

Detailed sensitivity analysis and discussion of the parameter setting can be found in Olbers et al. (2007) and Olbers and Lettmann (2007). For a time-constant wind forcing BARBI reaches a stationary state after its spin-up (Olbers et al., 2007), but for variable winds shows pronounced timevariability as a quasi-linear response to the non-stationary forcing (Olbers et al., 2007).

\subsection{Atmosphere-ocean coupling}

The two-way coupling between GS3LM and BARBI is organised as follows. The ocean circulation is driven by the atmospheric wind, where the surface wind stress is described by a bulk formula

$\boldsymbol{\tau}=c_{\mathrm{D}} \rho_{a}\left|\boldsymbol{V}_{\mathrm{s}}\right| \boldsymbol{v}_{\mathrm{s}}$.

Here, $c_{\mathrm{D}}=0.0013$ is the drag coefficient, $\rho_{a}=$ $1.25 \mathrm{~kg} \mathrm{~m}^{-3}$ is the standard surface air density, and $\left|\boldsymbol{V}_{\mathrm{s}}\right|=\sqrt{\left(\frac{\partial \psi_{S}}{\partial x}\right)^{2}+\left(\frac{\partial \psi_{S}}{\partial y}\right)^{2}}$ is the wind speed at the $10 \mathrm{~m}$ height. The 10 -m wind velocity vector reads $\boldsymbol{v}_{s}=\boldsymbol{k} \times \nabla \psi_{s}$, where $\mathbf{k}$ is the unit vector directed upward, and the streamfunction $\psi_{s}$ is taken proportional to that at $833 \mathrm{hPa}$ level, with the reduction coefficient $k=0.7$. According to the thermal wind equation written in isobaric coordinates, the horizontal wind velocity depends logarithmically on the pressure if the horizontal temperature gradient is approximately height-independent. Based on this assumption, the reduction coefficient value, $k=0.7$, was determined by a semi-empirical choice. The reduction coefficient $k=0.7$ means that, on average, the $10 \mathrm{~m}$ wind speed constitutes $70 \%$ of the wind speed at the lower model level of $833 \mathrm{hPa}$. In the NH the oceanic model is forced with interpolated annual mean (over 1986-1988) wind stress data from ECMWF analysis (Barnier et al., 1995) (surface density forcing is omitted). The backward influence of the ocean circulation on the atmosphere is achieved through the SST-related heat fluxes. They are described by a linearized bulk formula

$H=c_{\mathrm{H}} \rho_{a} c_{p}\left|\boldsymbol{V}_{\mathrm{S}}\right|(\mathrm{SST}-\mathrm{SAT})$

with the heat exchange coefficient $c_{\mathrm{H}}=c_{\mathrm{D}}$ and $\left|\boldsymbol{V}_{\mathrm{s}}\right|=$ $5 \mathrm{~m} \mathrm{~s}^{-1}$ is the standard wind speed at the $10 \mathrm{~m}$ height. In this formula, $c_{p}=1004 \mathrm{~m}^{2} \mathrm{~s}^{-2} \mathrm{~K}^{-1}$ is the specific heat at constant pressure, SAT abbreviates the surface air temperature; other notations are as in Eq. (1). The direct thermal forcing of the oceanic circulation is omitted (see also Appendix B). The use of $E$ as a prognostic variable in BARBI leads to a difficulty: the atmosphere is sensitive to the seawater temperature $T$ (specifically to SST), but indifferent to the salinity $S$ and to the seawater density (and so $E$-values). A problem arises to extract information on oceanographic variables, $T$ and $S$, that is contained in $E$ and translate it into the SST-terms. An important simplification permissible for SH oceans will be to assume that the basin-averaged vertical density stratification is mainly explained by $S$-values, whereas the density deviations specifying $E$ distribution are mainly determined by $T$-variations (e.g. Falcini et al., 2009).

In the thermally balanced model, a systematic heat exchange between the atmosphere and the ocean is not allowed, also because all other constitutive elements of the oceanic heat balance (radiative forcing, etc.) are not considered in this simplified framework. It means that the basin-averaged SST 


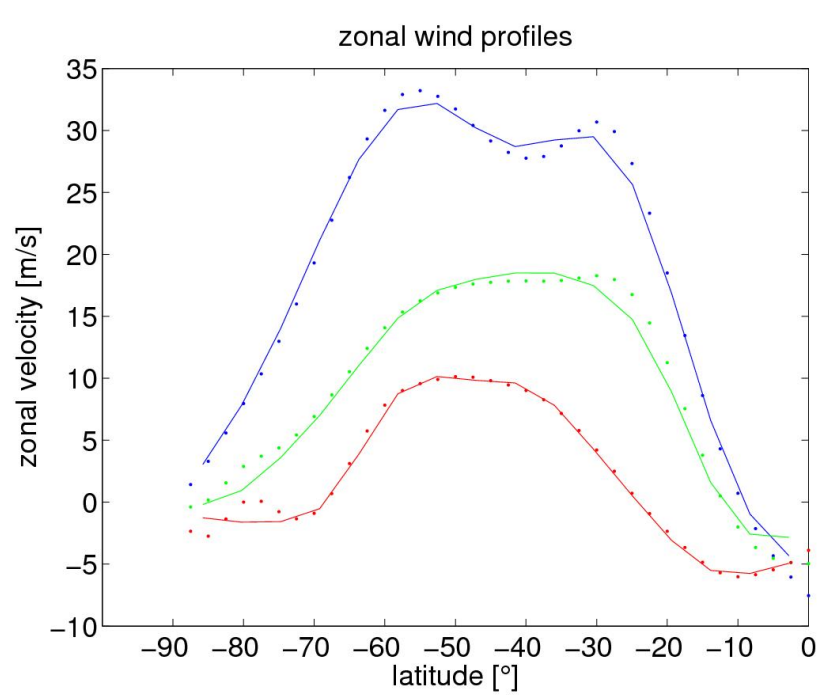

Fig. 3. Modelled (continuous) and observed (dotted) time-mean zonal wind profiles for the three model levels $833 \mathrm{hPa}$ (red), $500 \mathrm{hPa}$ (green) and $167 \mathrm{hPa}$ (blue) and corresponding vertical layers, respectively.

value should coincide with the analogously averaged SATvalue, and moreover cannot vary in time. The latter is due to intrinsic limitations imposed by the quasi-geostrophic nature of GS3LM (see also Appendix B); however, this constraint is not seen as a very restrictive one for the largely oceanic $(\approx 80 \%$ by area) SH. Therefore, the deviations of SST and SAT from this common time-constant value (hereafter, these temperature deviations are denoted as $\mathrm{SST}^{\prime}$ and $\mathrm{SAT}^{\prime}$ ) appear in Eq. (2). The details of $E$ to $\mathrm{SST}^{\prime}$ conversion are given in Appendix B, see especially Eq. (B1).

\section{Model results}

\subsection{Model experiment}

Initially, a 1000-yr spin-up run of BARBI from the state of rest without coupling to the atmospheric GS3LM was carried out. It was found that the oceanic circulation after $200 \mathrm{yr}$ reaches a quasi-stationary state with $\approx 140 \mathrm{~Sv}$. This stationary state has been used as an initial state for the further model integration. During $200 \mathrm{yrs}$ the atmospheric model was tuned towards NCEP-NCAR reanalysis data, since the forcing terms describing the atmosphere-ocean heat exchange are now taken into account (see, Appendix B) but SST'-values in them are temporarily set to zero. Finally, using the fine-tuned atmospheric module and a steady-state oceanic circulation, as an initial state, the fully coupled atmosphere-ocean model is run over $1000 \mathrm{yr}$ under perpetual SH winter conditions. The first $200 \mathrm{yr}$ of the coupled model run have been considered as spin up time and, therefore, results are presented for the following $800 \mathrm{yr}$.

\subsection{Model climatology}

Figure 3 shows the time-mean zonal wind profile over the last $800 \mathrm{yr}$ of the $1000 \mathrm{yr}$ long integration of the coupled model versus zonal wind profiles inferred from austral wintertime NCEP-NCAR reanalysis data. The latter have been computed after averaging the reanalysis data over three vertical atmospheric layers of approximately equal mass, instead of using individual pressure level data. It was done to capture the contribution of the stratospheric polar vortex. As visible in Fig. 3, the agreement between the modelled and the observed wind profiles is fairly good. The wind speed maximum situated at about $30^{\circ} \mathrm{S}$ at the middle and upper level corresponds to the subtropical jet (STJ). The second maximum in the upper level wind profile is due to the polar front jet (PFJ) across the South Pacific east of Australia during the austral winter. Together, STG and PFG compose a "split jet" ("double jet") structure over the South Pacific (e.g. BalsElsholz et al., 2001), which manifests itself in zonal-averaged wind profiles.

The atmospheric module exhibits skill in reproducing the polar vortex. This pattern is very persistent through all $800 \mathrm{yr}$ of model integration and clearly is exhibited in 800-yr averages (not shown), but the corresponding standard deviation as compared to the observations is rather small (not shown).

Figure $4 \mathrm{a}$ displays the last $10 \mathrm{yr}$ time slice of the coupled model run for the oceanic stream function, and $4 b-d$ presents the $1000 \mathrm{yr}$ long runs including the spin up period over 200 yr. Dark circles with numbers 1, 2, 3 in Fig. 4a mark three grid points across the Drake Passage for which a temporal behaviour of the streamfunction $\Psi$ is demonstrated in Fig. $4 \mathrm{~b}-$ d. After ca. $150 \mathrm{yr}$ the coupled system reaches an equilibrated state with a moderate, by $\approx 15-20 \%$, increase in $\Psi$-values in the Drake Passage, compared to an uncoupled spin-up run (not shown). These values remain within the range of experimentally observed values (see Sect. 2.4). The thick white lines describe the moving average of the chaotically fluctuating stream function.

\subsection{Model variability}

Figure $4 \mathrm{~b}-\mathrm{d}$ shows the transient behaviour of the streamfunction across the Drake Passage. Note that $\Psi$-values increase southward, consistent with the eastward flow of ACC. The $\Psi$-values in the southernmost grid point 3 characterises the total transport through the Drake Passage. The stream function fluctuates around a mean state with ups and downs indicating pronounced decadal and multi-decadal variability, displayed in Figs. 11b and 12c. Around the year 940 a strong reduction of the stream function occurs which persists over two decades.

The time-variance of $\Psi$ in grid point 3 (Drake Passage) is about $50 \mathrm{~Sv}$ (Fig. 4d) and corresponds to a mean ACC value of about $170 \mathrm{~Sv}$. In BARBI-only runs this variance vanishes for a time-constant wind forcing and, therefore, quantifies the 


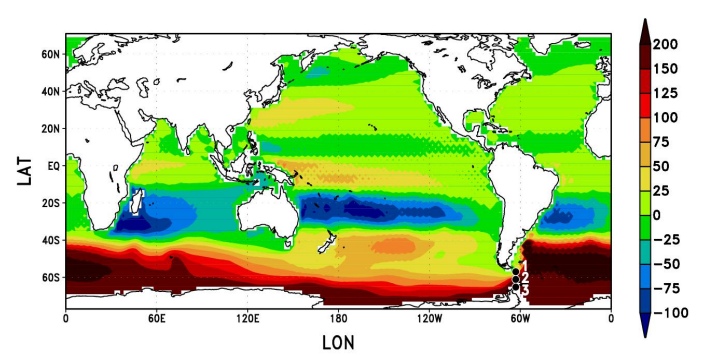

(a)

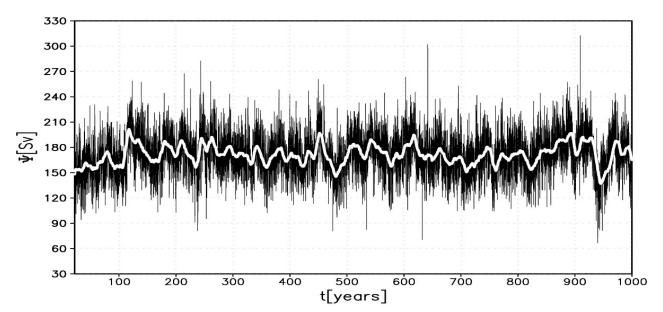

(c)

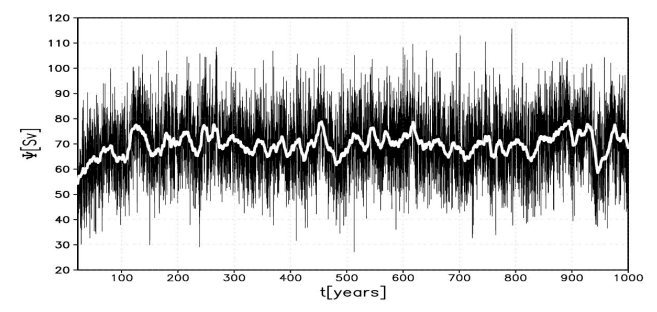

(b)

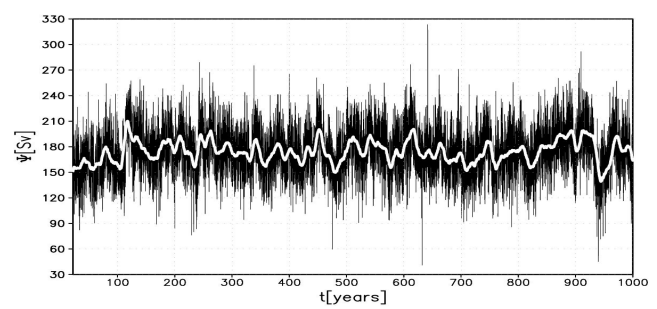

(d)

Fig. 4. (a) Time-mean of the oceanic streamfunction $\Psi$ (in Sv) over last $10 \mathrm{yr}$ of the coupled atmosphere-ocean model run. Numbers $1,2,3$ mark the grid points in the Drake Passage for which a transient behaviour of $\Psi$ is shown. White lines indicate the gliding mean of the stream function. (b) $\Psi$-values (Sv) for the grid point with coordinates $59^{\circ} \mathrm{S}$ and $91^{\circ} \mathrm{W}$ (point 1 in a) over $1000 \mathrm{yr}$. (c) The same as in (b), but for $61^{\circ} \mathrm{S}$ (point 2 in a). (d) The same as in (b) and (c), but for $63^{\circ} \mathrm{S}$ (point 3 in a)

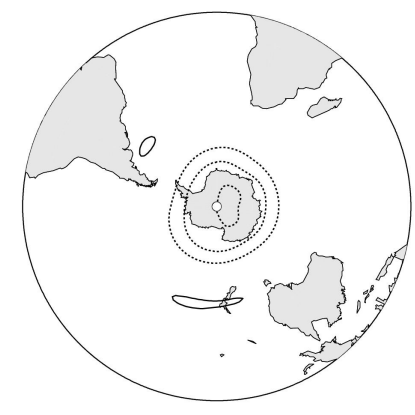

(a)

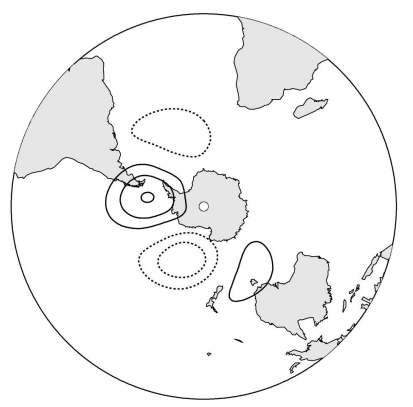

(d)

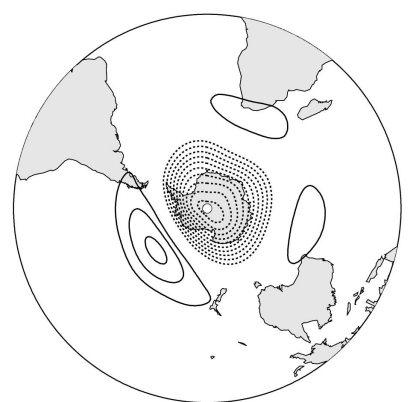

(b)

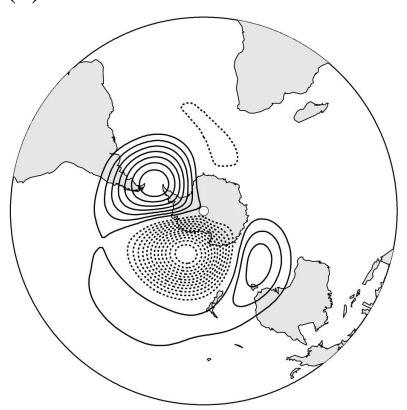

(e)

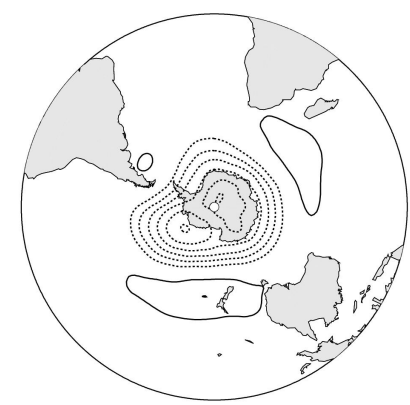

(c)

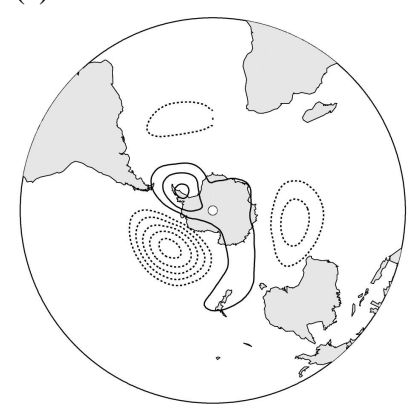

(f)

Fig. 5. (a) First EOF of $833 \mathrm{hPa}$ geopotential height for the $800 \mathrm{yr}$ run of the atmosphere-only model (16.4\% of explained variance). (b) First EOF of $833 \mathrm{hPa}$ geopotential height for the $800 \mathrm{yr}$ run of the coupled model (13.8\% of explained variance). (c) First EOF of observed austral wintertime geopotential height in the lowest model level (NCEP-NCAR reanalysis data for 1948-2003) (31.7\% of explained variance). (d) Second EOF of $833 \mathrm{hPa}$ geopotential height for the $800 \mathrm{yr}$ run of the atmosphere-only model (9.4\% of explained variance). (e) Second EOF of $833 \mathrm{hPa}$ geopotential height for the $800 \mathrm{yr}$ run of the coupled model (9.8\% of explained variance). (f) Second EOF of observed austral wintertime geopotential height in the lowest model level (NCEP-NCAR reanalysis data for 1948-2003) (12.2\% of explained variance). 


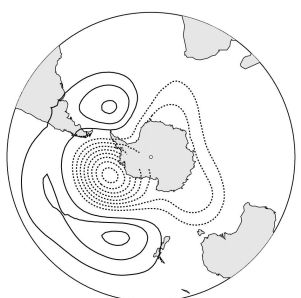

(a)

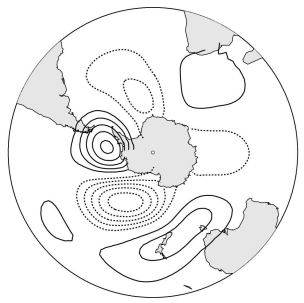

(e)

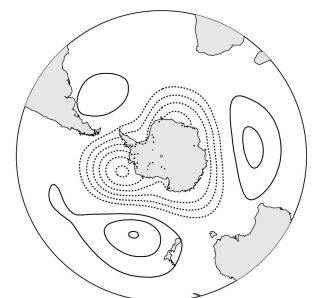

(b)

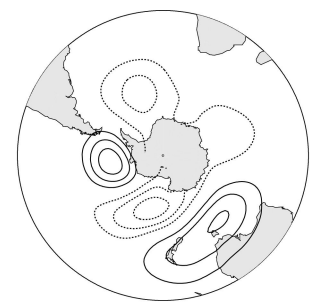

(f)

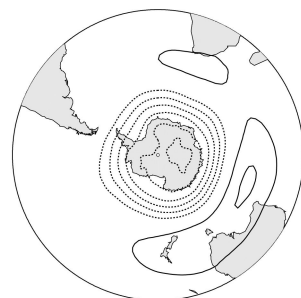

(c)

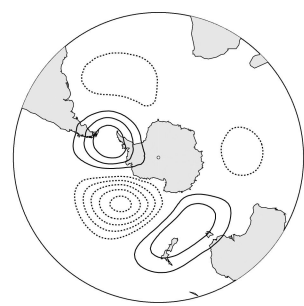

$(\mathrm{g})$

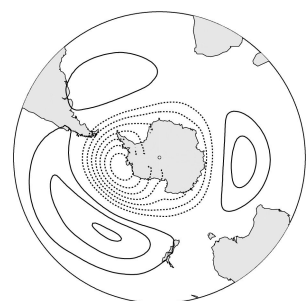

(d)

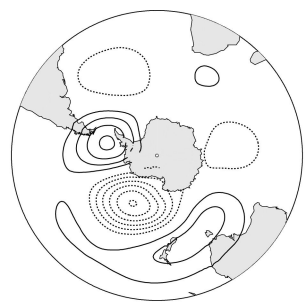

(h)

Fig. 6. (a) First EOF of $850 \mathrm{hPa}$ geopotential height for CMIP5, historical run, 1948-2003, HadGEM2-ES (24.0\% of explained variance). (b) The same as in (a) for GFDL-ESM2M (26.2\% of explained variance). (c) The same as in (a) for MPI-ESM-MR (29.6\% of explained variance). (d) The same as in (a) for CCSM4 (26.6\% of explained variance). (e) Second EOF of $850 \mathrm{hPa}$ geopotential height for CMIP5, historical run, 1948-2003, HadGEM2-ES (12.2\% of explained variance). (f) The same as in (e) for GFDL-ESM2M (18.2\% of explained variance). (g) The same as in (e) for MPI-ESM-MR (11.5\% of explained variance). (h) The same as in (e) for CCSM4 (15.9\% of explained variance).

coupling of the ocean model to its chaotically behaving atmospheric counterpart. There is an apparent correlation between fluctuating $\Psi$-values in Fig. 4c-d, which means that, to a large extent, the westerly flow in the southern part of Drake Passage (between $61^{\circ} \mathrm{S}$ and $63^{\circ} \mathrm{S}$ ) does experience strong time-variations, but without any climatic trend. The major part of transport variability through Drake Passage is explained by the fluctuating flow through its northern part between $61^{\circ} \mathrm{S}$ and the southernmost part of South America (Tierra del Fuego). In our model, this northern part of the flow explains about $50 \%$ of the total transport through Drake Passage.

What is the physics of model variability seen in Fig. 4 ? Does it originate in the atmospheric dynamics and the ocean redistributes or integrates it? The leading mode of lowfrequency variability in the $\mathrm{SH}$ troposphere is AAO/SAM (e.g. Thompson and Wallace, 2000) and the AAO index is defined as the leading principal component of the $850-\mathrm{hPa}$ geopotential height anomalies south of $20^{\circ} \mathrm{S}$ (Thompson and Wallace, 2000).

The AAO pattern was computed from monthly means of the model outputs since the main focus is on the lowfrequency variability. In the coupled model simulations, the principal structure of the AAO pattern with 3 centres surrounding Antarctica is reproduced versus observations at the $833 \mathrm{hPa}$ atmospheric model level (Fig. 5b-c), but the maxima are shifted in zonal direction and are not located at the observed geographical positions. The corresponding first EOF for the last $800 \mathrm{yr}$ of a $1000 \mathrm{yr}$ atmosphere GS3LM-only run is shown in Fig. 5a. The variance explained by the first EOF of the coupled model simulation is with $13.8 \%$ less than half of that of the NCEP reanalyses and weaker than those of the atmosphere-only model (16.4\%). The first EOF of the simplified atmosphere-only model is too zonal. Although the coupled model shows some improvements it does not reproduce the right position of the centre of action over the $\mathrm{SH}$ Pacific Ocean. Figure 5d-f display the second EOF for the atmosphere-only run, the coupled atmosphere-ocean simulation and for the NCEP data, respectively. The overall agreement in the spatial pattern of the second EOF in the coupled model with NCEP reanalyses is slightly better than in the first EOF. The amplitude of the second EOF in the coupled model is larger than in the atmosphere-only run and in the range of the CMIP5 models shown in Fig. 6. Additionally the explained variance is only slightly weaker in the coupled run $(9.8 \%)$ as in the NCEP data $(12.2 \%)$.

For comparison, Fig. 6 gives an impression on the range of variability patterns simulated by state-of-the-art coupled atmosphere-ocean-sea ice models. The patterns have been determined at $850 \mathrm{hPa}$ level for four arbitrarily chosen models from the CMIP5 ensemble (CCSM4, GFDL-ESM2M, HadGEM2-ES, MPI-ESM-MR, see Table 1 for further explanations). The same time period (1948-2003) as for the NCEP data has been analysed. The geopotential height fields have been taken from the historical simulations for the 20th century (Taylor et al., 2012) for which all forcings were included as observed values for past dates (atmospheric composition (including $\mathrm{CO}_{2}$ ) due to both anthropogenic and volcanic influences, solar forcing, emissions or concentrations 
Table 1. Summary of information on the CMIP5 models used in this study.

\begin{tabular}{llll}
\hline Modelling Center & Institute ID & Model Name & Reference \\
\hline National Center for Atmospheric Research & NCAR & CCSM4 & Gent et al. (2011) \\
NOAA Geophysical Fluid Dynamics Laboratory & NOAA GFDL & GFDL-ESM2M & Dunne et al. (2012) \\
Met Office Hadley Centre & MOHC & HadGEM2-ES & Collins et al. (2011), Jones et al. (2011) \\
Max Planck Institute for Meteorology & MPI-M & MPI-ESM-MR & Jungclaus et al. (2010) \\
\hline
\end{tabular}

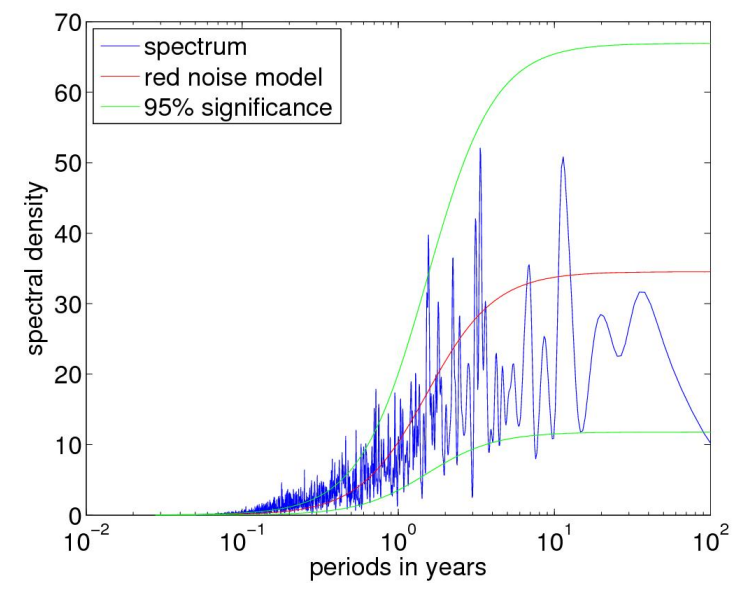

(a)

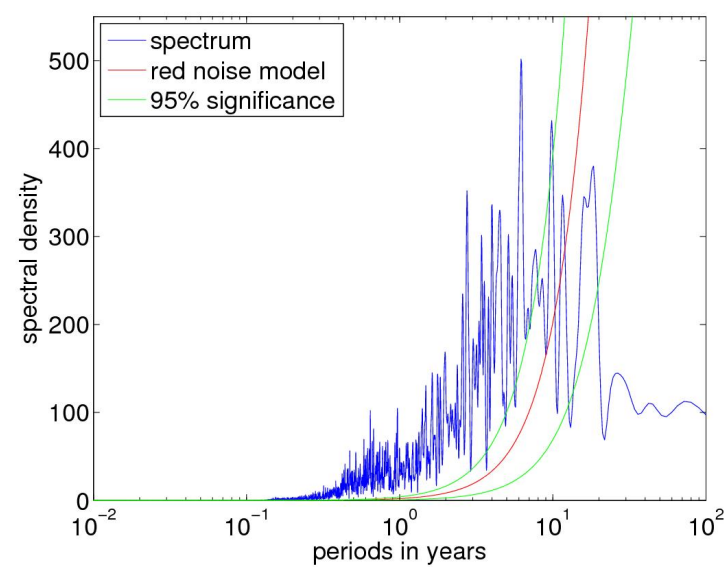

(b)

Fig. 7. (a) Power spectrum of PC 1 at $833 \mathrm{hPa}$ geopotential height for the atmosphere-only model. The last $800 \mathrm{yr}$ of a $1000 \mathrm{yr}$ run. (b) The same as in (a), but for the coupled model.

of short-lived species and natural and anthropogenic aerosols or their precursors, land use).

Figure 6a-d display the first EOF for winter (JJA) data, that is the AAO-pattern. The patterns simulated by HadGEM2-ES and GFDL-ESM2M resemble the observed structure very closely, whereas the patterns simulated by MPI-ESM-MR and CCSM4 display a more annular structure, as we detected for the simplified models (atmosphereonly, Fig. 5a and coupled model, Fig. 5b). The explained variances for the AAO patterns simulated by the complex models ranges from $24 \%$ to $30 \%$. The second patterns (Fig. 6e-h) display the observed circumpolar wave structures with wavenumber 3 , but with varying strength and slightly shifted positions of the centres of action. The explained variances for the wave-patterns ranges from $11 \%$ to $18 \%$. Qualitatively the variability patterns simulated by our simplified coupled model are in the wide range of teleconnection model variability patterns simulated by complex state-of-theart coupled circulation models. The first EOF of the simplified model is too zonal and does not reproduce the right position of the centre of action over the Pacific Ocean and its extension to the tropics visible in Fig. 6a-c. The agreement in the second EOF between the simplified and the CMIP5 models is better. The geographical extension to the tropical Pacific is still missing and could be a result of the applied quasi-geostrophic approximation in the atmospheric model.
It was tested whether the first EOFs are well separated from each other by applying the "rule-of-thumb" of North et al. (1982), taking into account the effective sampling size according to the formula given in Bretherton et al. (1999). The sampling errors of the respective eigenvalues for the first four EOFs are smaller than the distance between the neighbouring eigenvalues for the atmosphere-only run, the coupled runs as well as for the NCEP-data. Thus, the first four EOFs for all model runs and the NCEP data can be expected to be well separated and not mixed.

The oceanic BARBI model has been proven to be efficient in simulating the predominantly wind-driven Southern Ocean circulation, and the lower-level-only information from GS3LM is used to compute the acting wind stress. Therefore, the AAO as the leading mode of atmosphere-ocean dynamic interaction on long time scales and at mid- and high SH latitudes is reproduced satisfactorily, which gives an incentive to use the constructed coupled model in this study.

The too low explained variance in the first and the second EOF in the coupled model setup could be partly attributed to the relative coarse horizontal and vertical resolution of the oceanic model. As stated by Fanning and Weaver (1998) a higher ocean resolution is important for the excitation of stronger decadal-scale variability in idealised coupled atmosphere-ocean models due to the reduced parameterised diffusion. Goosse et al. (2010) mention a too weak 


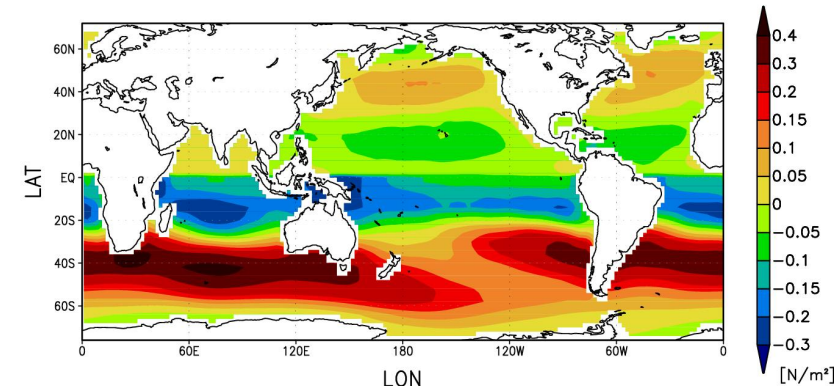

(a)

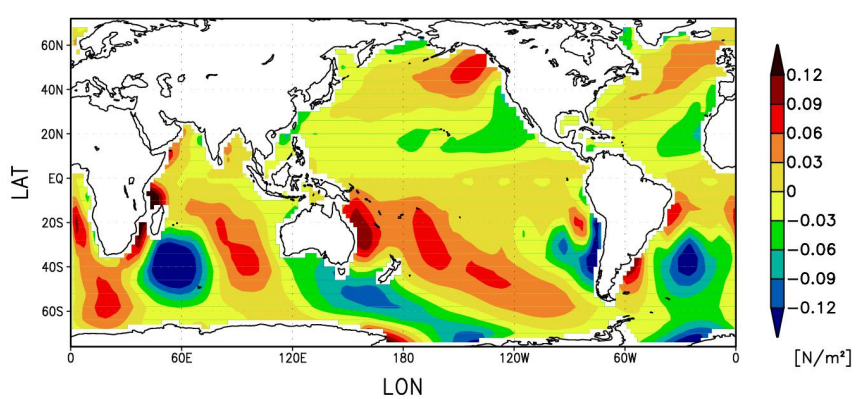

(b)

Fig. 8. (a) $800 \mathrm{yr}$ mean climatology of $\tau_{\mathrm{x}}\left(\mathrm{N} \mathrm{m}^{-2}\right)$ for the coupled model run. (b) The same as in (a), but for $\tau_{y}\left(\mathrm{~N} \mathrm{~m}^{-2}\right)$ (c)

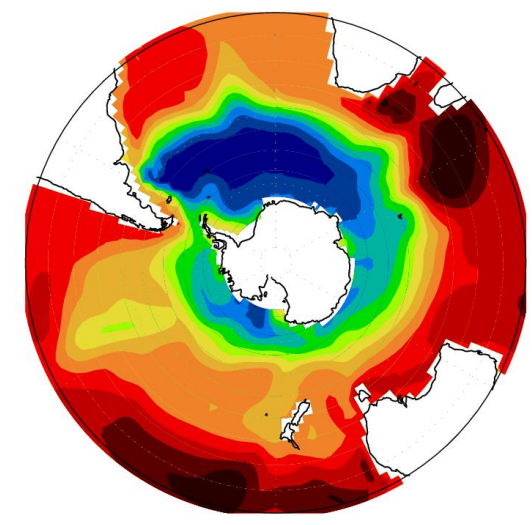

(a)

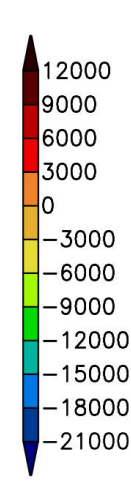

12000

6000

3000

$-3000$

$-6000$

$-9000$

15000

$-18000$

$(1000$

Fig. 9. (a) $800 \mathrm{yr}$ mean climatology of $E\left(\mathrm{~m}^{3} \mathrm{~s}^{-2}\right)$.

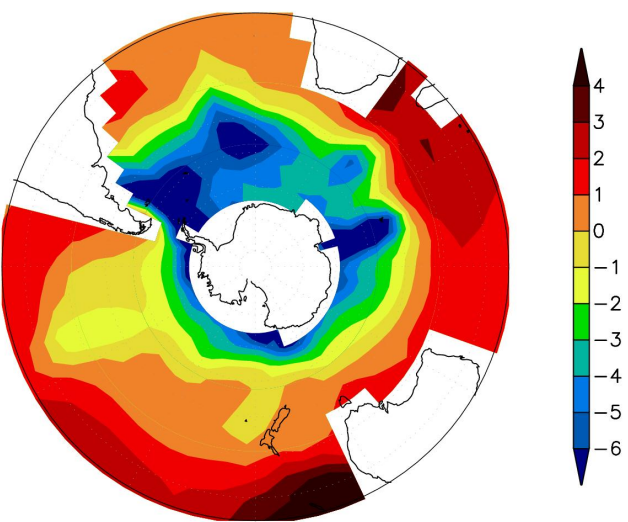

(b)

${ }^{-2}$ ). (b) The same as in (a), but for $S S T^{\prime}$ over the Southern Hemisphere (K).

atmospheric circulation in an Earth system model of intermediate complexity which contains a spectral three-layer atmospheric model similar to our approach, but with a different ocean model. Therefore, the impact of increased horizontal ocean resolution was investigated in the coupled model setup by carrying out simulations with $2^{\circ} \times 2^{\circ}$ longitude/latitude and with $4^{\circ} \times 2^{\circ}$ longitude/latitude resolution (not shown). The higher ocean resolution improved the results compared to observations. The impact of increased spectral resolution of the atmospheric model up to T42 resulting in a better resolution of the topography of the Andes and Antarctica will be investigated in a next step.

In our experiment, BARBI is forced by a chaotically behaving atmospheric GS3LM with significant deviations from red-noise model on monthly time-scales (Fig. 7). On this time-scale, the fluctuating wind stress drives the fast barotropic BARBI-subsystem, where the transport streamfunction $\Psi$ serves as the fast variable (Fig. 4b-c). Figure 8 describes the spatial pattern of the zonal and meridional components of the wind stress climatology in the coupled model simulations over the aforementioned last $800 \mathrm{yr}$ of a $1000 \mathrm{yr}$ long run. These wind stress components are similar to those of the uncoupled oceanic BARBI model described by Ol- bers and Lettmann (2007) and indicates a reliable interactive atmosphere-ocean coupling.

Figure $9 \mathrm{a}$ presents the $800 \mathrm{yr}$ mean climatology of the baroclinic potential energy $E$, whereas the field of SSTdeviations from the basin-average value $\left(\mathrm{SST}^{\prime}\right)$ is shown in Fig. 9b. There is a high correlation between $E$ and $\mathrm{SST}^{\prime}$, but the impact of variable oceanic depth $h$, see Eq. (B1), is clearly visible, too. The slow baroclinic BARBI-subsystem, quantified by the baroclinic potential energy $E$ and JEBARterm, effectively integrates the fast "stochastic" forcing implemented by the wind stress and the barotropic pumping action of the mean stratification (the first term on the righthand-side of (A2)).

On these long time scales the ocean imposes a feedback on the atmospheric circulation, through SST-variations which are inferred from the slow $E$-variable that dominates the lowfrequency variability in BARBI. The separation of slow and fast responses in BARBI has been demonstrated in Olbers and Lettmann (2007). The first and the second EOF for $\mathrm{SST}^{\prime}$ over the entire SH, shown in Fig. 10a-b indicate, that these leading variability patterns are dominated by processes in the Pacific. To enhance alternative variability patterns, which otherwise remain obscure within the hemispheric approach, 


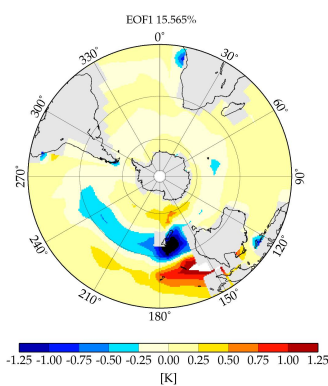

(a)

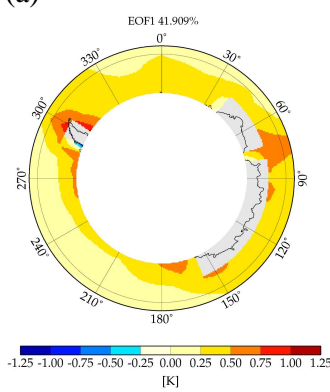

(c)

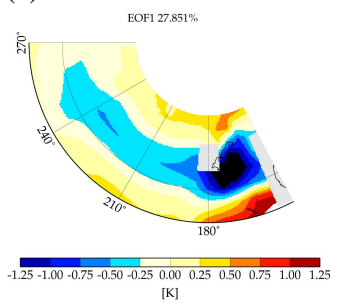

(e)

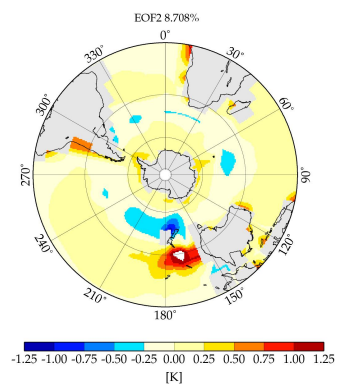

(b)

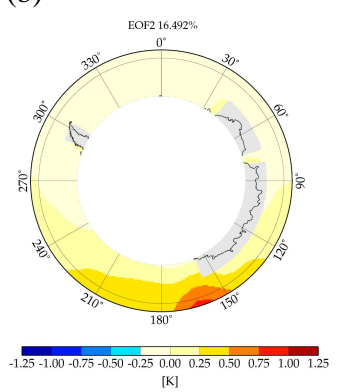

(d)

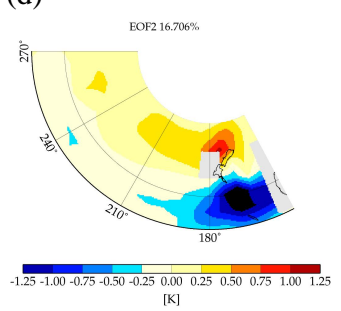

(f)

Fig. 10. (a) First EOF of $S S T^{\prime}$ over the Southern Hemisphere. (b) The same as in (a), but for the second EOF. (c) The same as in (a), but over the ACC $\left(60^{\circ}-70^{\circ} \mathrm{S}\right)$. (d) The same as in (c), but for the second EOF. (e) The same as in (a), but for the Southern Pacific region $\left(20^{\circ}-60^{\circ} \mathrm{S}, 152^{\circ} \mathrm{E}-90^{\circ} \mathrm{W}\right)$. (f) The same as in (e), but for the second EOF.

the SH ocean was subdivided into four domains, the Southern Pacific, the Southern Atlantic, the Southern Indian Ocean and the ACC (the Southern Ocean), and the EOF analysis has been applied to each of them. Here, we focus mainly on the ACC (a ring-like domain between $60^{\circ}$ and $70^{\circ} \mathrm{S}$ ) and we show the corresponding first and second EOF (Fig. 10cd). For comparison, the same EOFs, but for the Southern Pacific $\left(152^{\circ} \mathrm{E}-90^{\circ} \mathrm{W}, 20^{\circ}-60^{\circ} \mathrm{S}\right)$ are shown in Fig. 10e-f. The spatial patterns resemble those ones in Fig. 10a-b. These regional EOFs show interesting differing spectral behaviour explained in Fig. 12.

Figure 11a-b display the power spectra of the first PC of the monthly-averaged geopotential heights over the Southern Hemisphere and the $\mathrm{SST}^{\prime}$ over the ACC region of the coupled model. At long time-scales, the ocean is directly forced by the wind stress, because the spectrum of atmospheric fluctuations extend to low frequencies. Redistribution of variability towards long time-scales in the coupled model is clearly seen

in Fig. 7b if compared with Fig. 7a for the atmosphere-only model. Thus, enhanced ultra low-frequency variability evident in Fig. 7b leads to an increased wind forcing that drives BARBI on very long time-scales as visible in Fig. 11b. On those time-scales BARBI possesses its own intrinsic nonlinear dynamics, due to the nonlinearity inherent in Eq. (A2). So, an intricate positive feedback loop develops, which provides unique characters to low-frequency variability within this coupled model leading to enhanced spectral energy on decadal to multidecadal timescales as revealed by the power spectra of the first and second PC of the $\mathrm{SST}^{\prime}$ over the ACC region and of the first PC for the Southern Pacific shown in Fig. 11b-d.

Figure 12a-b display the local (colour) and global wavelet (black-white) spectra for the atmospheric PC 1 and PC2 of geopotential height at $833 \mathrm{hPa}$ over $1000 \mathrm{yr}$ of the coupled simulations. Figure $12 \mathrm{c}-\mathrm{d}$ show the wavelet spectra for the 1st and 2nd PC of SST' over the whole Southern Hemisphere and Fig. 12e-f present the wavelet spectra for the 1st and 2nd PC of SST' over the ACC Pacific region. The EOFs connected with these PCs are displayed in Fig. 10. The significance of the wavelet spectra has been tested by comparison to the spectra of a corresponding red noise process. Significant differences between observed and corresponding red noise spectra are determined by computing confidence levels and confidence intervals.

The atmospheric variations in Fig. 12a-b cover interannual and decadal time scales up to $20 \mathrm{yr}$. The $\mathrm{SST}^{\prime}$ variations in Fig. 12c-d show a slight accumulation of spectral density on longer time scales from 50 up to 130 years. Fig. 12e indicates a statistical significant multi-decadal peak around 50 $60 \mathrm{yr}$ periods in the ocean $\mathrm{SST}^{\prime}$ over the ACC region. Both, Figs. $11 \mathrm{~b}$ and $12 \mathrm{e}$ deliver evidence of a remarkable multidecadal variability in the ACC.

Figure 12 clearly indicates the generation of significant oceanic low-frequency variability and surface temperature fluctuations on the timescale of several decades in the Antarctic Circumpolar Current region in this simplified coupled atmosphere-ocean model. Some simulated peaks in the power spectra of oceanic variables coincide with dominant frequencies in the power spectra of the atmospheric variables, especially for the time periods from about 15 to $35 \mathrm{yr}$ with a maximum at about $20-25 \mathrm{yr}$.

\section{Conclusions}

A new simplified coupled atmosphere-ocean model with inherent nonlinear dynamics has been developed aiming at the examination of decadal and multi-decadal climate variability over mid- and high SH latitudes, arising in the model, and of the role of atmosphere-ocean interaction in altering and shaping it. By coupling the hemispheric quasigeostrophic atmospheric model with horizontal resolution T21 to a global ocean circulation model with a resolution 


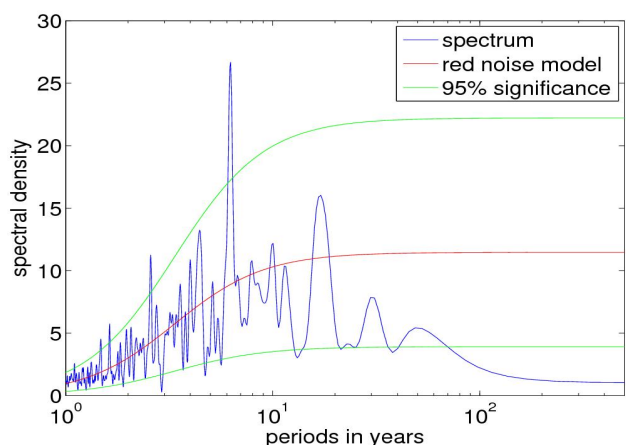

(a)

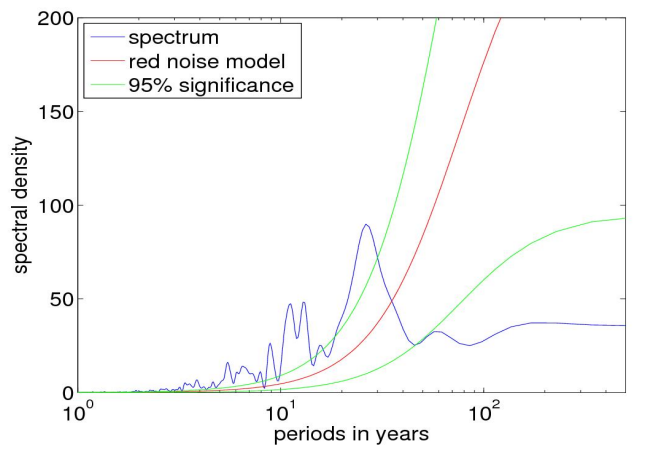

(c)

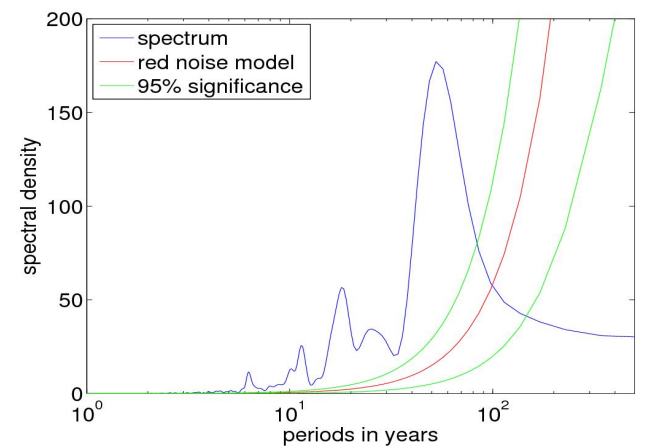

(b)

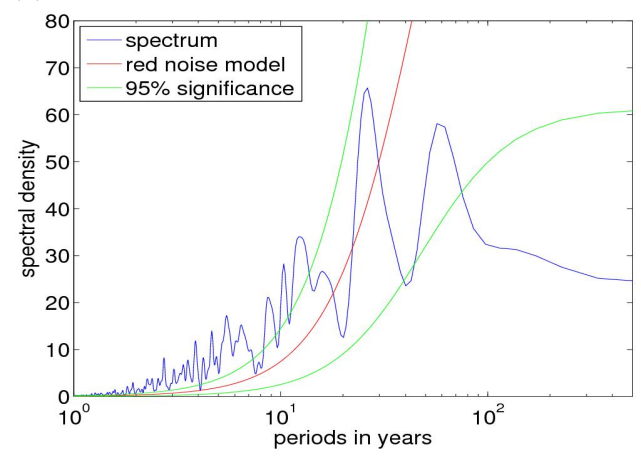

(d)

Fig. 11. (a) Power spectrum for the monthly-averaged PC 1 of the geopotential height at $833 \mathrm{hPa}$ model level for the coupled $800 \mathrm{yr}$ run. (b) The same as in (a) but for $S S T^{\prime}$ over the ACC. (c) The same as in (b) but for PC 2. (d) The same as in (b) but for the Southern Pacific.

of $2^{\circ} \times 2^{\circ}$ with simplified physics (the barotropic-baroclinicinteraction model BARBI), it was possible to simulate important qualitative aspects of large-scale atmospheric features of the extra-tropical atmospheric processes in the Southern Hemisphere. The coupled model is able to reproduce qualitative features of the first and the second EOF of $833 \mathrm{hPa}$ geopotential height, but underestimates the variance by a factor 2 compared to NCEP data.

Qualitatively the variability patterns simulated by our simplified coupled model are in the wide range of teleconnection patterns simulated by complex state-of-the-art coupled circulation models. The first EOF of the simplified model is too zonal and does not reproduce the position of the centre of action over the Pacific Ocean and its extension to the tropics visible in Fig. 6a, b and c. The agreement in the second EOF between the simplified and the CMIP5 models is better. The geographical extension to the tropical Pacific is still missing and could be a result of the applied quasi-geostrophic approximation. Based on preliminary investigations with the atmosphere-only model the variance of the simplified coupled model could be further increased using a higher atmospheric resolution. The transport properties of the Southern Ocean circulation are in qualitative accord with the essential features of observations. The oceanic BARBI model successfully simulated the wind-driven oceanic circulation in the SH.
Due to the coupling, there is significant oceanic lowfrequency variability apparent in the SST anomaly $\left(\mathrm{SST}^{\prime}\right.$ ) time-variations and demonstrated in Figs. 10-12. The first EOF of the simulated $\mathrm{SST}^{\prime}$ shows a similarity with observed patterns (e.g. Doney et al., 2003, 2007). The spectral analysis of the temporal evolution of the dominant variability patterns makes it clear that while the power spectra for the atmosphere-only model are more white (Fig. 6a), the power and wavelet spectra of atmospheric variables for the coupled model demonstrate more apparent red behaviour (Figs. 6b, 11a and 12a). Crucial to, thus, enhanced redness is the parameterisation of interaction between the atmosphere and the ocean.

Theoretically, the effect of reddening is described, e.g., by Vallis (2010). The ocean acts as an integrator of variability on short time scales, which leads to shifting of the maxima in the atmospheric spectra to low frequencies. Following Hasselmann (1976), Vallis (2010) characterises the reddening of the atmospheric variability by the ocean as the null hypothesis for climate variability. The effect of reddening is obviously present in our coupled model, as follows from Figs. 7a, b, 11a and 12a. It was also detected that significant spectral peaks are observed in the power spectra of oceanic variables, which coincide with the dominant frequencies in the power spectra of the atmospheric variables (cf. Figs. 11a, b, d). Particularly noteworthy are the time periods from about 15 to $35 \mathrm{yr}$ with a 


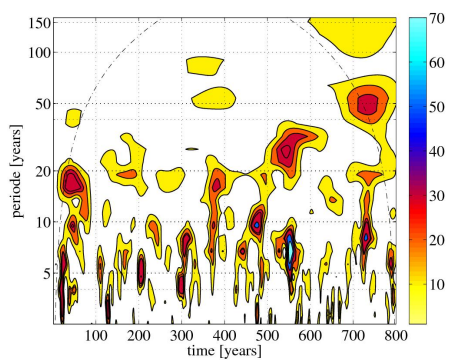

(a)

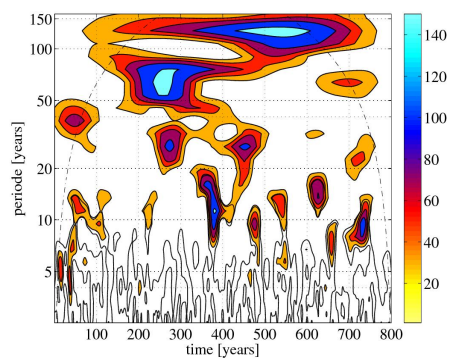

(c)

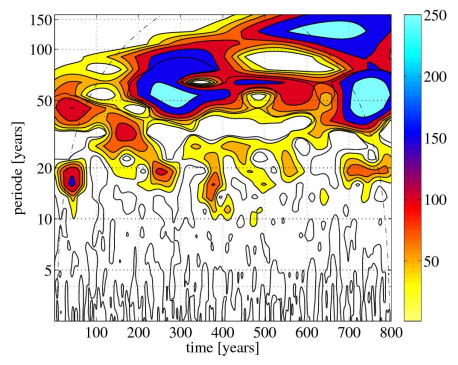

(e)
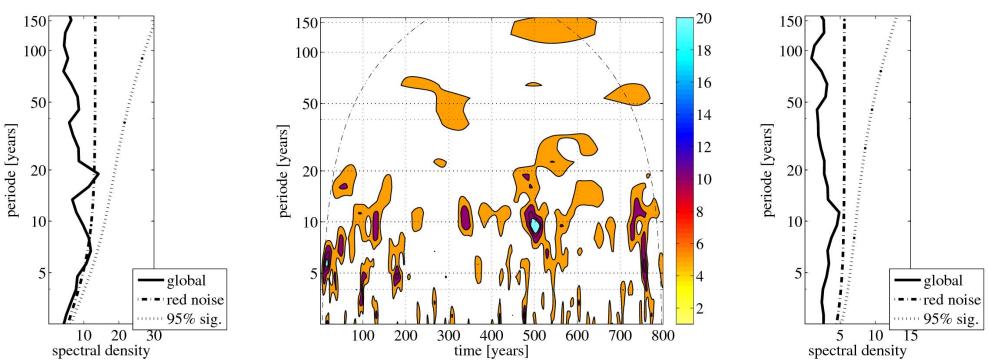

(b)
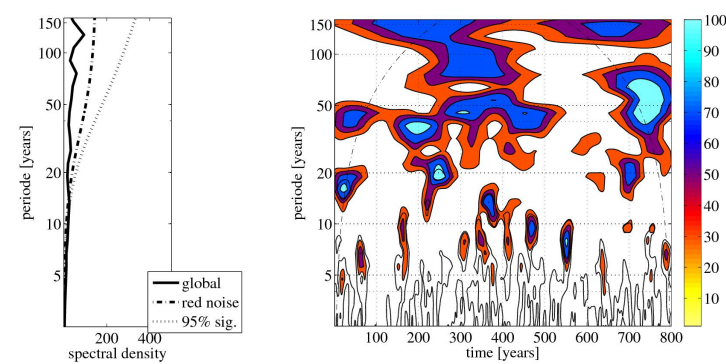

(d)
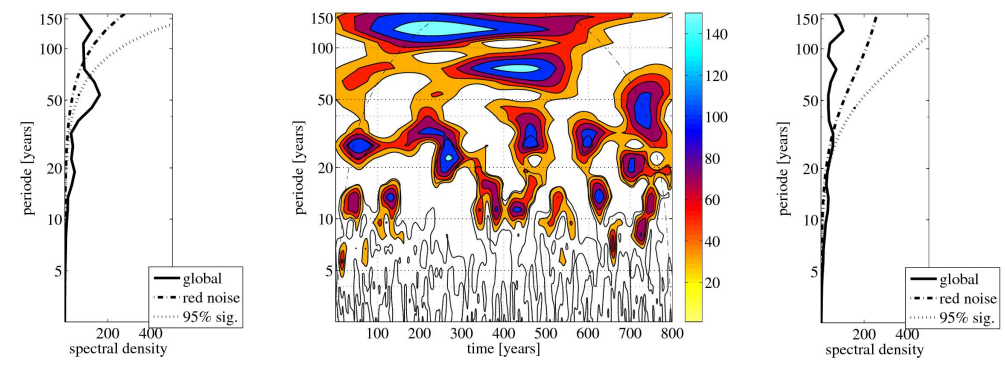

(f)

Fig. 12. (a) Wavelet spectrum for the monthly-averaged PC 1 of the geopotential height at $833 \mathrm{hPa}$ model level for the $1000 \mathrm{yr}$ run. (b) The same as in (a), but for PC 2. (c) The same as in (a), but for $S S T^{\prime}$ over the Southern Hemisphere. (d) The same as in (b), but for $S S T^{\prime}$ over the Southern Hemisphere. (e) The same as in (a), but for $S S T^{\prime}$ over the ACC. (f) The same as in (b), but for $S S T^{\prime}$ over the ACC.

maximum at about 20-25 yr. Also, Farneti and Vallis (2009) reported an oscillation at about $20 \mathrm{yr}$. However, these authors used a three-dimensional atmosphere-ocean-land-ice global circulation model of intermediate complexity and associate the oscillation with the meridional overturning circulation (MOC). The MOC in BARBI is poorly reproduced, since only the first density moment (baroclinic potential energy) is retained and so the vertical resolution is relatively low. In addition, our calculated power spectra show significant peaks at time-periods around 50-60 yr. For globally averaged boreal winter mean SST, a peak at approximately $64 \mathrm{yr}$ period was also found in numerical simulations by Opsteegh et al. (1998) who associated the peak with large scale variability in the Southern Ocean. Time-periods of 15-30 and 65-70 yr are indeed observed in the real ocean; some evidence comes from the frequency analysis of proxy data (Mantua, 2002).

In this study, it was assumed that the momentum and heat exchange coefficients ( $c_{\mathrm{D}}$ and $\left.c_{\mathrm{H}}\right)$ in Eqs. (1) and (2) are basi- cally the same. However, this is valid only for a certain range of $c_{D}$-values and an inequality $c_{\mathrm{D}} \neq c_{\mathrm{H}}$ (see e.g. Liu et al., 1979; Gill, 1982) could be accounted for in the model, in an attempt to improve its "realism". Further experimentation with the model is challenging, especially as far as it regards the atmospheric circulation regime behaviour dependent on various model parameters, including the coupling constants $c_{\mathrm{D}}$ and $c_{\mathrm{H}}$. The horizontal resolution of the atmospheric and oceanic modules should be increased to be able to simulate more realistic wind patterns and finer scale ocean circulation systems such as Humboldt Current and the overall current system in the southeast Pacific (cf. Dávila and Figueroa, 2001). Increasing vertical resolution in the atmospheric module and accounting for higher density moments in the oceanic module would also increase the realism of the simulations with the coupled model.

The atmosphere-ocean system constitutes the fundamental subsystem of the Earth climate system, and this offers 
an opportunity of basic research of the climate variability with the use of simplified coupled atmosphere-ocean models. Among these models our model fills the gap between the models of so-called intermediate complexity, but with GCM-flavour (e.g. Farneti and Vallis, 2009) and simplified low-order box climate models (e.g. Roebber, 1995). The presented results contribute to a better understanding of the origin of internally generated climate variability in the atmosphere-ocean system.

\section{Appendix A}

\section{BARBI model}

BARBI can be summarised by the set of equations (cf. Olbers and Eden, 2003):

$$
\begin{aligned}
& \frac{\partial}{\partial t} \nabla \cdot\left(\frac{1}{h} \nabla \Psi\right)+J\left(\Psi, \frac{f}{h}\right)=J\left(E, \frac{1}{h}\right) \\
& ,+A_{h} \nabla \cdot\left(\frac{1}{h} \nabla \cdot \nabla_{\otimes}^{2} \Psi\right)+\frac{c_{\mathrm{D}} \rho_{a}\left|\mathbf{V}_{\mathrm{s}}\right|}{\rho_{0}} \nabla \cdot\left(\frac{1}{h} \nabla \psi_{s}\right) \\
& \frac{\partial E}{\partial t}+h J\left(\Psi, \frac{E}{h^{2}}\right)=\frac{N^{2}}{3} J\left(\Psi, \frac{h^{2}}{2}\right) \\
& +\frac{N^{2}}{3} \nabla \cdot \boldsymbol{u}^{*}+K_{h} \nabla^{2} E-\mu E, \\
& \frac{\partial}{\partial t} \boldsymbol{u}^{*}+f \boldsymbol{k} \times \boldsymbol{u}^{*}=-\frac{1}{3}\left(\nabla E^{*}-h^{2} \nabla E\right) \\
& +A_{h} \nabla^{2} \boldsymbol{u}^{*}-\frac{h^{2}}{3} \frac{c_{\mathrm{D}} \rho_{a} \mid \mathbf{V}_{\mathrm{s}} \text { pdflatex } \mid}{\rho_{0}}\left(\boldsymbol{k} \times \nabla \psi_{s}\right) .
\end{aligned}
$$

Here, $h$ is the ocean depth, $E=\int_{-h}^{0} g\left(\rho / \rho_{0}\right) z d z$ is the potential energy referred to the sea surface level $z=0$ and scaled by a constant reference density $\rho_{0}=1035 \mathrm{~kg} \mathrm{~m}^{-3}$; $\rho$ is the density deviation from a mean background profile of density, $g$ is the acceleration due to gravity and $z$-axis is directed upward. Mean background stratification is described by the Brunt-Väisälä frequency $N$. This is taken as being constant in this study and we use $N=0.0026 \mathrm{~s}^{-1}$. In Eq. (A1), $\Psi$ is the streamfunction of the barotropic flux velocity $\boldsymbol{U}=\int_{-h}^{0} \boldsymbol{u} d z$, where $\boldsymbol{u}$ is the (total) horizontal velocity; $\nabla$ is the horizontal Nabla-operator, $\nabla_{\otimes}^{2} \equiv h \nabla$. $\left(h^{-1} \nabla\right)$ is similar to the Laplacian $\nabla^{2}$, but modified by the depth $h$ in order to ensure positive definiteness of the viscous dissipation function; $J$ denotes the Jacobian and $f$ is the Coriolis parameter. Notations in the two last terms in Eqs. (A1) and (A3), which are pertinent to the atmosphereocean interaction, are explained in the main text. The baroclinic velocity moment in Eqs. (A2) and (A3) is defined by $\boldsymbol{u}^{*}=\int_{-h}^{0}(\boldsymbol{u}-\boldsymbol{U} / h) z^{2} d z$. To close Eqs. (A1)-(A3) it is used that $E^{*} \equiv \int_{-h}^{0} g\left(\rho / \rho_{0}\right) z^{3} d z=\gamma h^{2} E, \gamma=1-6 / \pi^{2} \approx$
0.3921, which ensures an accurate description of large-scale wave propagation in BARBI (Olbers and Eden, 2003). Coefficients $A_{h}=20000 \mathrm{~m}^{2} \mathrm{~s}^{-1}$ and $K_{h}=1000 \mathrm{~m}^{2} \mathrm{~s}^{-1}$ stand for a large-scale momentum diffusivity and a turbulent heat (salt) diffusivity, respectively, based on the isopycnal parameterisation of meso-scale oceanic eddy effects by Gent and McWilliams (1990). The dissipation coefficient of $E$ is $\mu=1.5 \times 10^{-10} \mathrm{~s}^{-1}\left(\mu^{-1} \approx 222 \mathrm{yr}\right)$.

\section{Appendix B}

\section{Thermal coupling}

The thermal coupling is applied to the atmosphere only. As follows from Eq. (2) and discussion in Sect. 2.5, it is described with a linear forcing term proportional to $\mathrm{SST}^{\prime}-$ $\mathrm{SAT}^{\prime}$. By the hydrostatic law and for a standard temperature lapse rate, $\mathrm{SAT}^{\prime}$ is related to the air temperature deviations from corresponding ocean basin-averaged values at the auxiliary model levels 333 and $667 \mathrm{hPa}: \mathrm{SAT}^{\prime} \approx 1.080 T_{333}^{\prime} \approx$ $1.234 T_{667}^{\prime}$ (for the same longitude and latitude). It is further used that two thirds of the incoming heat is spent on warming of the lower half of the atmosphere (mean level $667 \mathrm{hPa}$ ), and the remaining one third goes to its upper half (mean level $333 \mathrm{hPa}$ ). In the prognostic equations for $T_{667}^{\prime \prime}$ and $T_{333}^{\prime \prime}$ (double primes denote deviations from hemisphere-averaged values) it corresponds to an additional linear forcing term with a relaxation time-scale of 20 and 35 days, correspondingly. The forcing is applied to those grid points of the atmospheric model which are above ocean grid points. Otherwise, it is set to zero. A systematic error, arising from a difference between the hemispheric-wide and the ocean-basin-wide average (in general, $T_{667}^{\prime \prime} \neq T_{667}^{\prime}, T_{333}^{\prime \prime} \neq T_{333}^{\prime}$ ), see also Sect. 2.5, is compensated by the applied fine-tuning of GS3LM during the 8000 day period; see Sect. 3.1.

To parameterise $\mathrm{SST}^{\prime}$, we use the formula

$\mathrm{SS} T^{\prime} \approx \frac{5.6 E}{\alpha g h^{2}}+\frac{\beta S^{\prime}}{\alpha}$.

Here $\alpha$ is the constant coefficient of seawater thermal expansion, $\beta$ is the constant coefficient of seawater haline contraction, and $S^{\prime}$ is the deviation of near surface salinity from its basin-averaged value; other notations see in Appendix A. Equation (B1) stems from an assumption of the quadratic dependence on depth of the seawater density and of vanishing of the vertical density gradient at the sea bottom. Substituting these parabolic density profiles into $E$ and $E^{*} \approx 0.3921 h^{2} E$ (see, Appendix A) leads to a set of two equations to determine the surface density anomaly for a given $E$-value. A positive (negative) anomaly of $E$ recasts in terms of a negative (positive) surface density anomaly, because $E$ is referred to the level $z=0$ and the sea depth $z$ is ascribed negative values. Afterwards a linear equation of state for seawater is used to obtain Eq. (B1). Alternative parameterizations of 
the vertical density profile lead essentially to the same formula (B1) but with somewhat differing coefficients before $E$. However, keeping in mind all schematics of our coupled model, Eq. (B1) is used in the study. It is also used that the impact of salinity on the water density is generally of opposite sign to that of the temperature, and in the Southern Ocean these two effects hold in proportion 1:3 or even 1:5 (Levitus and Boyer, 1994). In a practical realisation of the model, the second right-hand side term in Eq. (B1) is omitted, but instead a reduction factor, 0.7 , is introduced before $\alpha$ in the denominator of the first right-hand-side term in this equation.

Acknowledgements. We acknowledge the work of Matthias Kollosche who took active part in adapting the atmospheric model to the Southern Hemisphere. We appreciate the help of Sergey Danilov from AWI Bremerhaven. We thank two anonymous reviewers for their careful review of the manuscript. We acknowledge the World Climate Research Programme's Working Group on Coupled Modelling, which is responsible for CMIP, and we thank the climate modeling groups (listed in Table 1 of this paper) for producing and making available their model output. For CMIP the US Department of Energy's Programme for Climate Model Diagnosis and Intercomparison provides coordinating support and led development of software infrastructure in partnership with the Global Organization for Earth System Science Portals.

Edited by: W. Hazeleger

\section{References}

Bals-Elsholz, T. M., Atallah, E. H., Bosart, L. F., Wasula, T. A., Cempa, M. J., and Lupo, A. R.: The Wintertime Southern Hemisphere Split Jet: Structure, Variability, and Evolution, J. Climate, 14, 4191-4215, 2001.

Barnier, B., Siefridt, L., and Marchesiello, P.: Thermal forcing for a global ocean circulation using a three year climatology of ECMWF analysis, J. Mar. Syst., 6, 363-380, 1995.

Bretherton, C. S., Widmann, M., Dymnikov, V., Wallace, J., and Bladé, I.: The effective number of spatial degrees of freedom of a time-varying field, J. Climate, 12, 1990-2009, 1999.

Collins, W. J., Bellouin, N., Doutriaux-Boucher, M., Gedney, N., Halloran, P., Hinton, T., Hughes, J., Jones, C. D., Joshi, M., Liddicoat, S., Martin, G., O’Connor, F., Rae, J., Senior, C., Sitch, S., Totterdell, I., Wiltshire, A., and Woodward, S.: Development and evaluation of an Earth-System model - HadGEM2, Geosci. Model Dev., 4, 1051-1075, doi:10.5194/gmd-4-10512011, 2011.

Cunningham, S. A., Alderson, S. G., King, B. A., and Brandon, M. A.: Transport and variability of the Antarctic Circumpolar Current in Drake Passage, J. Geophys. Res., 108, 8084, doi:10.1029/2001JC001147, 2003.

Dávila, P. M. and Figueroa, D.: Comparison of the analysed surface winds from ECMWF and NCEP with observable data, over the southeastern Pacific $\left(35^{\circ} \mathrm{S}-62^{\circ} \mathrm{S}, 70^{\circ} \mathrm{W}-90^{\circ} \mathrm{W}\right)$, Aust. Meteorol. Mag., 50, 279-293, 2001.
Doney, S. C., Yeager, S., Danabasoglu, G., Large, W. G., and McWilliams, J. C.: Modeling global oceanic inter-annual variability (1958-1997): Simulation design and model-data evaluation, NCAR Tech. Note, NCAR/TN-452+STR, National Center for Atmospheric Research, Boulder, Colorado, 48 pp., 2003.

Doney, S. C., Yeager, S., Danabasoglu, G., Large, W. G., and McWilliams, J. C.: Mechanisms governing interannual variability of upper-ocean temperature in a global hindcast simulation, J. Phys. Oceanogr., 37, 1918-1938, 2007.

Dunne, J. P., John, J., Adcroft, A., Griffies, S. M., Hallberg, R. W., Shevliakova, E., Stouffer, R. J., Cooke, W. F., Dunne, K. A., Harrison, M. J., Krasting, J. P., Malyshev, S. P., Milly, C. D., Phillipps, P., Sentman, L. T., Samuels, B. L., Spelman, M. J., Winton, M., Wittenberg, A. T., and Zadeh, N.: GFDL's ESM2 global coupled climate-carbon Earth System Models Part I: Physical formulation and baseline simulation characteristics, J. Climate, in press, doi:10.1175/JCLI-D-11-00560.1, 2012.

Falcini, F., Iudicone, D., and Salusti, E.: Potential vorticity estimates of absolute velocities on the Ross Sea shelf, Deep Sea Res. Pt. I: Oceanogr. Res., 56, 314-329, doi:10.1016/j.dsr.2008.10.005, 2009.

Fanning, A. F. and Weaver, A. J.: Thermohaline variability: The effects of horizontal resolution and diffusion, J. Climate, 11, 709715, 1998.

Farneti, R. and Vallis, G. K.: Mechanisms of interdecadal climate variability and the role of ocean-atmosphere coupling, Clim. Dynam., 36, 289-308, doi:10.1007/s00382-009-0674-9, 2009.

Gent, P. R. and McWilliams, J. C.: Isopycnal mixing in ocean circulation models, J. Phys. Oceanogr., 20, 150-155, 1990.

Gent, P. R., Danabasoglu, G., Donner, L. J., Holland, M. M., Hunke, E. C., Jayne, S. R., Lawrence, D. M., Neale, R. B., Rasch, P. J., Vertenstein, M., Worley, P. H., Yang, Z.-L., and Zhang, M.: The Community Climate System Model Version 4, J. Climate, 24, 4973-4991, 2011.

Gill, A. E.: Atmosphere-Ocean dynamics, Academic Press, NY, 1982.

Goosse, H., Brovkin, V., Fichefet, T., Haarsma, R., Huybrechts, P., Jongma, J., Mouchet, A., Selten, F., Barriat, P.-Y., Campin, J.M., Deleersnijder, E., Driesschaert, E., Goelzer, H., Janssens, I., Loutre, M.-F., Morales Maqueda, M. A., Opsteegh, T., Mathieu, P.-P., Munhoven, G., Pettersson, E. J., Renssen, H., Roche, D. M., Schaeffer, M., Tartinville, B., Timmermann, A., and Weber, S. L.: Description of the Earth system model of intermediate complexity LOVECLIM version 1.2, Geosci. Model Dev., 3, 603-633, doi:10.5194/gmd-3-603-2010, 2010.

Haarsma, R. J., Selten, F. M., and Opsteegh, J. D.: On the mechanism of the Antarctic Circumpolar Wave, J. Climate, 13, 14611480, 2000.

Hasselmann, K.: Stochastic climate models, part I: theory, Tellus, 28, 473-485, 1976.

Hogg, A. M. and Blundell, J. R.: Interdecadal variability of the Southern Ocean, J. Phys. Oceanogr., 36, 1626-1645, 2006.

Hogg, A. M., Dewar, W. K., Killworth, P. D., and Blundell, J. R.: A Quasi-Geostrophic Coupled Model (Q-GCM), Mon. Wea. Rev., 10, 2261-2278, 2003.

Hughes, C. W., Meredith, M. P., and Heywood, K.: Wind-driven transport fluctuations through Drake Passage: a Southern Mode, J. Phys. Oceanogr., 29, 1971-1992, 1999. 
James, I. N. and James, P. M.: Spatial structure of ultra-low frequency variability of the flow in a simple atmospheric circulation model, Q. J. Roy. Meteor. Soc., 118, 1211-1233, 1992.

Jones, C. D., Hughes, J. K., Bellouin, N., Hardiman, S. C., Jones, G. S., Knight, J., Liddicoat, S., O'Connor, F. M., Andres, R. J., Bell, C., Boo, K.-O., Bozzo, A., Butchart, N., Cadule, P., Corbin, K. D., Doutriaux-Boucher, M., Friedlingstein, P., Gornall, J., Gray, L., Halloran, P. R., Hurtt, G., Ingram, W. J., Lamarque, J.-F., Law, R. M., Meinshausen, M., Osprey, S., Palin, E. J., Parsons Chini, L., Raddatz, T., Sanderson, M. G., Sellar, A. A., Schurer, A., Valdes, P., Wood, N., Woodward, S., Yoshioka, M., and Zerroukat, M.: The HadGEM2-ES implementation of CMIP5 centennial simulations, Geosci. Model Dev., 4, 543-570, doi:10.5194/gmd-4-543-2011, 2011.

Jungclaus, J. H., Lorenz, S. J., Timmreck, C., Reick, C. H., Brovkin, V., Six, K., Segschneider, J., Giorgetta, M. A., Crowley, T. J., Pongratz, J., Krivova, N. A., Vieira, L. E., Solanki, S. K., Klocke, D., Botzet, M., Esch, M., Gayler, V., Haak, H., Raddatz, T. J., Roeckner, E., Schnur, R., Widmann, H., Claussen, M., Stevens, B., and Marotzke, J.: Climate and carbon-cycle variability over the last millennium, Clim. Past, 6, 723-737, doi:10.5194/cp-6723-2010, 2010.

Levitus, S. and Boyer, T. P.: World ocean atlas 1994. US Department of Commerse, NOAA, NESDIS, Washington DC, 1994.

Liu, W. T., Katsaros, K. B., and Businger, J. A.: Bulk parametrization of air-sea exchanges of heat and water vapor including the molecular constraints at the interface, J. Atmos. Sci., 36, 17221735, 1979.

Mantua, N. J. and Hare, S. R.: The Pacific Decadal Oscillation, J. Oceanography, 58, 35-44, 2002.

Nigam, S., Chung, C., and DeWeaver, E.: ENSO diabatic heating in ECMWF and NCEP-NCAR reanalysis, and NCAR CCM3 simulation, J. Climate, 13, 3152-3171, 2000.

North, G. R., Bell, T. L., Cahalan, R. F., and Moeng, F. J.: Sampling errors in the estimation of empirical orthogonal functions, Mon. Wea. Rev., 110, 699-706, 1982.

Olbers, D. and Eden, C.: A simplified general circulation model for a baroclinic ocean with topography. Part I: theory, waves and wind-driven circulations, J. Phys. Oceanogr., 33, 2719-2737, 2003.
Olbers, D. and Lettmann, K.: Barotropic and baroclinic processes in the transport variability of the Antarctic Circumpolar Current, Ocean Dynam., 57, 559-578, doi:10.1007/s10236-007-0126-1, 2007.

Olbers, D., Lettmann, K., and Timmermann, R.: Six circumpolar currents - on the forcing of the Antarctic Circumpolar Current by wind and mixing, Ocean Dynam., 57, 12-31, 2007.

Opsteegh, J. D., Haarsma, R. J., Selten, F. M., and Kattenberg, A.: ECBILT: a dynamic alternative to mixed boundary conditions in ocean models, Tellus, 50A, 348-367, 1998.

Pacanowski, R. C.: MOM 2 Version 2.0 (Beta) Documentation User's Guide and Reference Manuel, GFDL Ocean Technical Report 3.2., 1996.

Pacanowski, R. C. and Griffies, S. M.: MOM 3.0 Manuel, NOAA/Geophysical Fluid Dynamics Laboratory, Princeton, USA 08542, 2000.

Roebber, P. J.: Climate variability in a low-order coupled atmosphere-ocean model, Tellus, 47A, 473-494, 1995.

Sarkisyan, A. S. and Ivanov, V. F.: Joint effect of baroclinicity and bottom relief as an important factor in the dynamics of sea currents, Akad. Nauk Atmos. Oceanic Phys., 7, 173-188, 1971.

Sempf, M., Dethloff, K., Handorf, D., and Kurgansky, M. V.: Idealized modeling of the northern annular mode: orographic and thermal impacts, Atmos. Sci. Lett., 6, 140-144, doi:10.1002/asl.106, 2005.

Sempf, M., Dethloff, K., Handorf, D., and Kurgansky, M. V.: Towards understanding the dynamical origin of atmospheric regime behaviour in a baroclinic model, J. Atmos. Sci., 64, 887-904, 2007a.

Sempf, M., Dethloff, K., Handorf, D., and Kurgansky, M. V.: Circulation regimes due to attractor merging in atmospheric models, J. Atmos. Sci., 64, 2029-2044, 2007b.

Taylor, K., Stouffer, R. J., and Meehl, G. A.: An Overview of CMIP5 and the experiment design, B. Am. Meteor. Soc., 93, 485-498, 2012.

Thompson, D. W. J. and Wallace, J. M.: Annular modes in the extratropical circulation. Part I: month-to-month variability, J. Climate, 13, 1000-1016, 2000.

Vallis, G. K.: Mechanisms of climate variability from years to decades, in: Stochastic Physics and Climate Modelling, edited by: Palmer, T. and Williams, P., Cambridge University Press, Cambridge, 1-34, 2010. 